\title{
Artigo
}

\section{A União Europeia e a crise que não é somente migratória}

The European Union and the crisis which is not only migratory

Adriana dos Santos Corrêa ${ }^{1}$

Adriana Kirchof de Brum²

DOI: $10.5752 /$ P.1809-6182.2017v15.n1.p 44

\section{Resumo}

A partir de 2015, a politica de asilo europeia passou por uma série de mudanças. Este artigo busca analisar os impactos institucionais causados pela crise migratória na União Europeia e identificar a sua interferência nas relaçôes do bloco.

Palavras-chave: Politica de Asilo; Crise Migratória; União Europeia.

\section{Abstract}

As of 2015, European asylum policy has undergone a series of changes. This article aims to analyze the institutional impacts caused by the migratory crisis in the European Union and to identify and their interference in the bloc's relations.

Keywords: Asylum Policy; Migratory Crisis; European Union.

1. Bacharel em Relações Internacionais e Mestranda no Programa de Pós-Graduação em Fronteiras e Direitos Humanos da Universidade Federal da Grande Dourados. Dourados/Brasil ORCID: 000-0002-0019-0428.

2. Doutora em Economia e professora no Programa de Pós-Graduação em Fronteiras e Direitos Humanos da Universidade Federal da Grande Dourados. Dourados/Brasil ORCID: 0000-0002-9153-1039. 


\section{INTRODUÇÃO}

A Europa viveu em 2015 o ápice de uma crise humanitária que possui precedentes históricos. É o resultado de conflitos que assolam regióes do Oriente Médio e do Continente Africano, fruto de governos ditatoriais e outros conflitos internos com grande influência de potências internacionais. O Reino Unido, a Suécia e a Alemanha estão entre os países europeus que mais receberam imigrantes e refugiados desde 2015.

Medidas foram tomadas para conter o fluxo de solicitantes de refúgio rumo à Europa. Uma das medidas mais polêmicas foi o Acordo UE-Turquia, que foi severamente criticado pelo Alto Comissariado das Naçôes Unidas para Refugiados (ACNUR) por violar princípios da Convenção de 1951 sobre o Estatuto do Refugiado aos quais os membros da União Europeia são signatários. Após este acordo uma série de outras medidas de contenção foi adotada, observa-se deste entáo uma deterioraçáo na saúde e demais direitos daqueles que ficam retidos em campos de refugiados ou abrigos temporários, e as viagens tornaram-se cada vez mais perigosas.

Os Estados Membros da União Europeia (UE) possuem acordos comuns sobre o tema da migraçáo e refúgio desde a institucionalização do bloco em 1992 com o Tratado de Maastricht. O Sistema Europeu Comum de Asilo possui como base as disposiçóes da Convenção de Dublin de 1990 que estabelece os critérios e mecanismos de determinação do Estado Membro responsável pela análise de um pedido de proteção internacional apresentado por um nacional de um país terceiro ou por um apátrida no território de qualquer Estado da UE. As medidas institucionais historicamente adotadas pela comunidade europeia para lidar com os refugiados passam por uma crise multidimensional desde 2015, que contribuiu, sobretudo, para uma falha sistemática da solidariedade internacional dos Estados Membros. Através de uma pesquisa bibliográfica qualitativa, o presente trabalho tem como objetivo analisar os impactos institucionais que a crise de refugiados tem gerado nos últimos anos na Uniấo Europeia e identificar as formas com que estes impactos influenciam nas relações de integração do bloco.

$\mathrm{Na}$ segunda seção serão apresentados os principais acordos internos da Uniấo Europeia que tratam da imigraçâo e do refúgio. Em especial, as contribuiçōes da "Convenção de Dublin" para o embasamento do modelo europeu de imigração. Trata-se de um acordo interno que regulamenta sobre a determinação do Estado responsável pela análise de pedido de asilo apresentado num Estado membro da Comunidade Europeia. Em seguida se faz algumas reflexôes sobre as instabilidades intrabloco causadas após algumas mudanças importantes deste acordo com o objetivo de "distribuir as responsabilidades" da crise humanitária entre os Estados membros.

$\mathrm{Na}$ terceira seção será apresentado um panorama atual do refúgio na Europa e seu desdobramento a partir 2015, e as várias formas de contenção do fluxo migratório adotadas por alguns Estados isoladamente e do bloco como um todo, como é o caso do Acordo UE-Turquia. Na última seção é aprofundada a análise acerca dos impactos institucionais gerados pelo grande fluxo de solicitantes de refúgio que chegam à Europa e como isso tem gerado algumas instabilidades nas relações entre os Estados Membros em múltiplas agendas.

\section{Acordos internos da União Europeia sobre migração e refúgio}

A criação da Comunidade Econômica Europeia (CEE) em 1957 teve a imigração enquanto um dos temas de maior preocupação para o bloco, pois se enxergava a alta capacidade de atração que 
a comunidade europeia despertaria no processo de integração econômica, considerando que esta passava por um período de desenvolvimento crescente do seu espaço de livre circulaçáo de bens, serviços, capital e pessoas.

Durante o fortalecimento do processo integrativo, foi assinado o acordo de Schengen (1984) entre França, Alemanha, Bélgica, Países Baixos e Luxemburgo. Esta foi uma proposta desafiadora no campo da imigração, uma vez que determinou a extinção do controle de pessoas das fronteiras internas entre os países supracitados, mas reforçava o controle das fronteiras externas do espaço territorial desses países a países terceiros, impedindo a entrada dos imigrantes sem documentos e aqueles cujos pedidos de asilo não foram aceitos (MAMEDE, 2015; MENDES, 2016).

Apesar do acordo de Schengen ter sido criado antes da institucionalização da União Europeia que se deu por meio do Tratado e Maastricht em 1992, esta política de imigração foi incorporada pela UE em 1997 pelo Tratado de Amsterdá. Este tratado sinalizou uma unidade na política europeia sobre a imigração, pois este era antes um assunto de exclusiva responsabilidade de cada Estado nacional e que considerando a ressalva feita por alguns Estados, passou a fazer parte do Direito Comunitário ${ }^{3}$ da Uniâo Europeia (MAMEDE, 2015).

Segundo Piçarra o processo de estruturação do Sistema Europeu Comum de Asilo (SECA) se pautou normativamente em quatro diretivas e dois regulamentos, as diretivas são: qualificação, proteção temporária, procedimentos e acolhimento. Estas estão ligadas a designação de questôes materiais necessárias para cumprir as normas de proteção. Já

3. A União Europeia forma uma ordem jurídica comunitária que é independente e autônoma em relação aos Estados que a compóem. Sua estrutura compreende diversas instituiçôes políticas e jurídicas que são responsáveis pela construçáo e desenvolvimento dos objetivos comunitários. O conjunto das regras e princípios que regulam esta estrutura constitui um novo ramo do direito chamado Direito Comunitário (LIMA FILHO, 2006). sobre os regulamentos, o principal é a atual versão da Convenção de Dublin (Regulamento de Dublin III), e o segundo regulamento é o sistema informático Eurodac (European Asylum Dactyloscopy Database) que foi criado para a aplicação efetiva do primeiro (PIÇARRA, 2016).

A Convenção de Dublin teve a sua primeira versão assinada em 1990, ratificada em 1992 e entrou em vigor no seu primeiro texto em 1997. Esta convecção estabelece os critérios e mecanismos de determinação do Estado Membro responsável pela análise de um pedido de proteção internacional apresentado por um nacional de um país terceiro ou por um apátrida no território de qualquer Estado Membro da UE, inclusive nas fronteiras ou zonas de trânsito. Cada pedido deve ser analisado por um único Estado membro, aquele que for o primeiro a receber o pedido de refúgio se tornará responsável por tais critérios de determinação do status de refugiado (UNIÃO EUROPEIA, 1992).

Nos últimos anos foram feitas várias críticas sobre texto original da Convenção de Dublin, isso ocorreu principalmente pela crise migratória de refugiados que chegaram à Europa á partir de 2015. Nessas condições o critério do Estado de primeira entrada, onde geralmente os pedidos são feitos, assumiu uma relevância desproporcional para os efeitos da determinação do Estado responsável pelos critérios de concessão do refúgio. Países como a Itália e a Grécia enfrentam uma situação de emergência por serem os Estados de entrada da maioria das rotas de imigração para a Europa (MAMEDE, 2015; PIÇARRA, 2016). Um projeto aprovado em outubro de 2017 pela Comissáo de Liberdades Cívicas da UE institui um sistema automático e permanente de realocação de solicitantes de refúgio, como uma medida ainda que sutil de a UE ajudar os países que recebem um enorme fluxo de imigrantes e refugiados (ANSA BRASIL, 2017). 


\section{O panorama do refúgio na UE e medidas de contenção}

Segundo dados oficiais do ACNUR, em 2015 as principais portas de entrada de imigrantes solicitantes de refúgio na Europa eram Espanha, Itália e a Grécia. No ano de 2015, considerado o ápice da crise humanitária, chegaram à Espanha (por terra e pelo mar) cerca de 16.300 pessoas. Na Itália a chegada foi majoritariamente pelo mar, cerca de 153.800 solicitantes de refúgio e este número foi ainda maior na Grécia, 856.700 pessoas que também fizeram um trajeto extremamente arriscado pelo mar. Nos anos seguintes este número sofreu algumas variaçóes consideráveis.

Tabela 1- Panorama da chegada de refugiados e imigrantes ò Europa de 2015 a 2018

\begin{tabular}{c|c|c|c}
\hline & Espanha & Itália & Grécia \\
\hline 2015 & 16.300 & 153.800 & 856.700 \\
\hline 2016 & 14.100 & 181.400 & 176.800 \\
\hline 2017 & 28.300 & 119.400 & 35.400 \\
\hline 2018 (até jul.) & 27.600 & 18.500 & 26.000 \\
\hline
\end{tabular}

Fonte: Elaborado pelas autoras com dados extraídos de Acnur (2018).

As principais origens do grande fluxo de imigrantes e refugiados que chegaram à Europa pelas rotas apresentadas na Tabela 1 são: Síria, Iraque, Tunísia, Eritreia, Marrocos, Afeganistão, Mali, Sudão, República Democrática do Congo, Nigéria e Palestina. É importante ressaltar o alto número de mortes e desaparecidos durante essas travessias, cerca de 2.427 pessoas em 2017 e mais de 1.500 entre janeiro e julho de 2018 (ACNUR, 2018).

Milhares de pessoas continuaram tentando alcançar Europa em busca de proteção internacional e reunificação familiar, juntamente com muitos outros que viajam por razóes diferentes, incluindo os aspectos econômicos e oportunidades educacionais. Em outras fronteiras europeias, incluindo nos Balcãs, a açóes de algumas autoridades fronteiriças tem sido a de "empurrar para trás" refugiados e migrantes de dentro de seu território para um país vizinho, muitas vezes negando acesso a procedimentos de asilo e, em muitos casos, recorrendo à violência (ACNUR, 2018). Essa "estratégia" de barrar o fluxo de imigrantes e refugiados adquiriu um caráter institucional mais forte com a assinatura do Acordo UE-Turquia.

Um acordo de "contenção" foi assinado entre dirigentes da União Europeia e da Turquia e entrou em vigor em 2016, seu objetivo era barrar o fluxo de migração irregular através do país com destino à Europa. O acordo prevê que a UE devolverá à Turquia todos os imigrantes irregulares que cheguem às ilhas gregas provenientes da Turquia a partir de 20 de março de 2016, que por cada sírio devolvido à Turquia, outro sírio proveniente da mesma será instalado na UE. Para a viabilidade do acordo, a UE concordou em acelerar a liberalização de vistos aos turcos, relançar as negociaçóes de adesão ao bloco e aumentar de 3 para 6 bilhóes de euros a ajuda à Turquia até 2018 para melhorar as condiçôes de vida dos refugiados sírios no país. Desta forma, as autoridades turcas se comprometeram a desenvolver novas leis para outorgar trabalho aos refugiados dentro de seu país, e buscar medidas internas que diminuam as migraçóes ilegais (ARIAS, 2017; CONSELHO EUROPEU, 2016).

O conjunto de gráficos presentes na Figura 1 demonstram respectivamente os deferimentos em primeira instância de solicitaçóes gerais de refúgio que chegaram à Europa no primeiro semestre de 2018, e depois esses dados divididos entre as principais nacionalidades dos solicitantes: sírios, afegãos e iraquianos. Os gráficos também trazem dados sobre outros status que vieram a ser atribuído aos solicitantes que não foram considerados refugiados pela UE de acordo com a Convenção de 1951: o status de proteção subsidiária, o status humanitário e ainda aqueles que tiveram o pedido rejeitado e que provavelmente terão de deixar a Europa. 
Figura 1- Decisões sobre os pedidos de asilo de janeiro a abril de 2018.

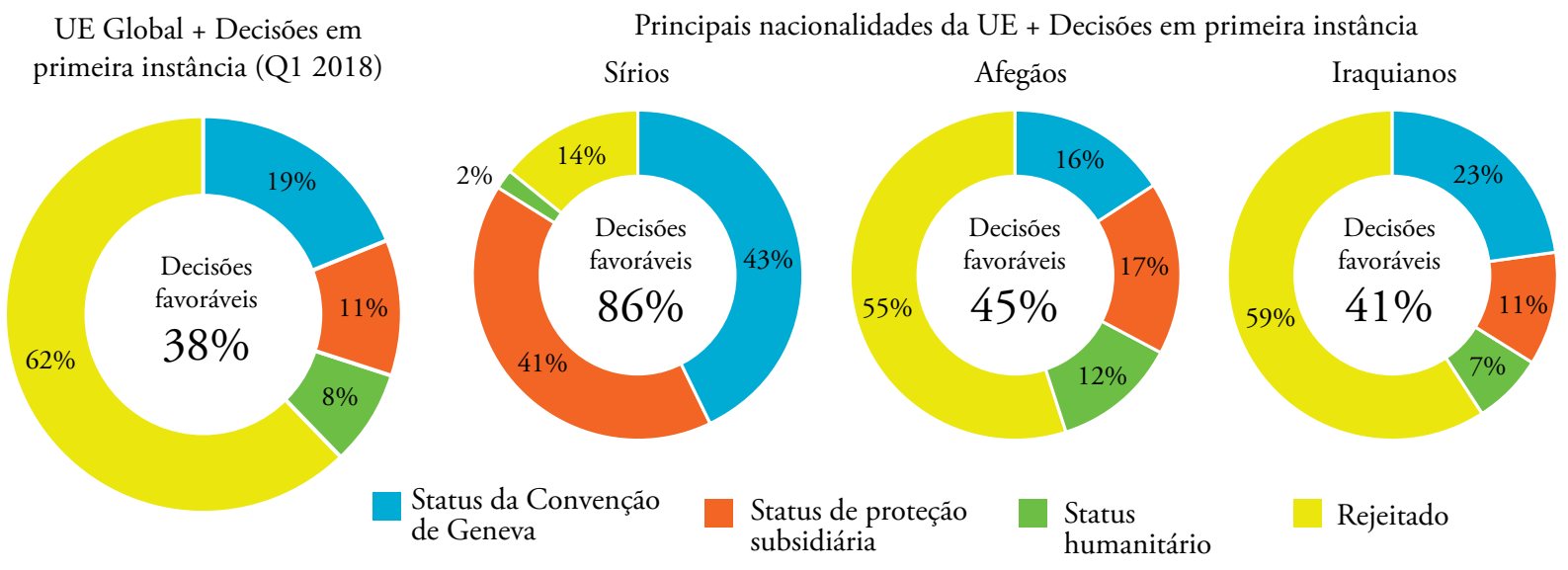

Fonte: ACNUR, 2018.

Os gráficos da Figura 1 nos mostram em geral que a UE deferiu em primeira instância cerca de 38\% das solicitaçôes entre janeiro e abril de 2018. O número de rejeiçốes é bem maior, e quando analisamos as origens dos principais pedidos ligamos essas rejeições ao viés securitizador das medidas adotadas pela UE para barrar o fluxo de solicitantes de asilo. Outra problemática está relacionada à atribuição de outros status que não a do refúgio a alguém que esteja sofrendo algum tipo de perseguição, pois este fica vulnerável a não receber a proteção adequada e ainda corre o risco de ser "devolvido" ao país de origem por não estar sendo amparado pelo Estatuto dos Refugiados.

A União Europeia em geral tem recebido inúmeras críticas sobre as tais medidas de contenção e em relaçẫo à distribuição desequilibrada de reponsabilidade entre os Estados Membros e principalmente sobre a falta de solidariedade dentro do próprio bloco, pois há uma enorme resistência dos membros em alterar as resoluções da Convenção de Dublin. O discurso de securitização das imigraçóes se tornou cada vez mais comum no território europeu após os atentados que ocorreram na Inglaterra, França, Alemanha nos últimos anos. A figura a seguir traz um gráfico com os principais países da UE que aceitaram asilar refugiados e seus respectivos números.
Figura 2 - Países da UE que mois aceitarom refugiados entre janeiro e abril de 2018 45.760

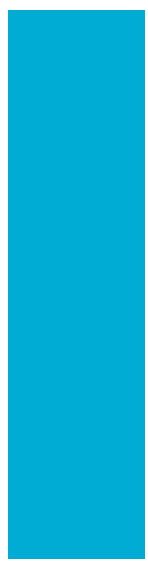
34.020

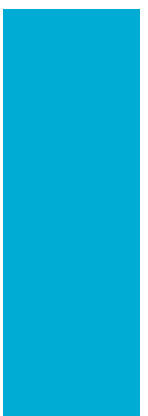

21.965

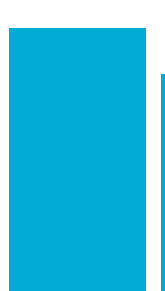

18.070

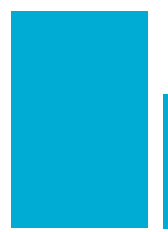

11.180

Alemanha

França

Itália

Grécia

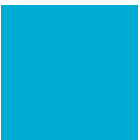

Reino Unido

Fonte: ACNUR, 2018.

Os dados trazidos no gráfico da Figura 2 nos mostra a disparidade do número de refugiados recebidos entre os Estados Membros da UE. No gráfico estâo expostos somente dados dos maiores receptores, esse número é ainda mais desigual em relação a outros países como a Estônia, Croácia, Eslováquia, Eslovênia, Portugal e Luxemburgo que receberam desde 2015 muito pouco refugiados se comparado aos outros Estados (EUROSTATE, 2015). 
Segundo Carlota Arias, ações de contenção como esta que barram o direito de solicitação de asilo ou ainda concede outros status que não o de refugiado contribuem para diversas violaçóes ao Direito Internacional. No caso do Acordo com a Turquia, os solicitantes de asilo seriam afastados da possibilidade de que lhes seja outorgado o status de refugiado, e pela possibilidade de que o estado de vulnerabilidade destas pessoas seja intensificado por um processo não adequado de proteção (ARIAS, 2017, p. 73). Há um reconhecimento por parte dos organismos internacionais de proteção aos refugiados de que a UE se encontra em uma situação muito complicada na busca por "respostas" a muitos desafios colocados, mas alerta para a necessidade de uma melhoria na articulação de políticas internas e externas mais eficazes para que as tomadas de decisão sobre a migraçôes caminhem de acordo com o Direito Internacional (ARIAS, 2017).

\section{Crise migratória e a crise relacionamento intrabloco}

Desde o aumento do fluxo de imigrantes para a Europa, a tensão entre Estados Membros (em especial Estados do Norte vs Estados do Sul) se acirrou. A Itália e a Grécia têm sido censuradas pelo restante do bloco e responsabilizados pela excessiva permeabilidade das suas fronteiras e a inabilidade de conter a imigração irregular. Ao mesmo tempo, ambos os países são acusados de violar direitos humanos dos requerentes de asilo (TRIANDAFYLLIDOU; AMBROSINI, 2011 apud RIJO, 2017).

Em geral os países de entrada e passagem dos imigrantes irregulares e solicitantes de refúgio na UE são alvos de críticas pelos outros Estados por "não carregarem" as responsabilidades de acolhimento a longo prazo, a ser suportado por países de destino como a Suécia e a Alemanha. Atentados em solo europeu bem como a dificuldade de lidar com o grande contingente de solicitantes de refúgio levantaram receios da população sobre a temática, além contribuir para o ressurgimento das forças de extrema direita. Estes grupos têm ganhado grande influência política, utilizando o medo da população e o descontentamento com chamada a partilha de responsabilidades entre Estados Membros, enquanto fundamento para a adoção de medidas anti-integracionistas.

Com todos os desdobramentos políticos e midiáticos acerca da crise humanitária na Europa a temática da imigração e asilo se tornou topo da agenda dos Estados Membros e das principais instituições da UE. Os efeitos da crise são muito críticos ao processo integrativo do bloco. Há um crescimento do euroceticismo acerca das autoridades nacionais europeias, especialmente em países como a Dinamarca, Holanda e França. O Reino Unido se tornou um caso claro da adoçâo de medidas conservadoras e nacionalistas, em salvaguarda dos interesses do Estado em detrimento dos acordos da comunidade europeia. Em março de 2017 os britânicos oficializaram o desejo de saída do bloco e a crise migratória foi um dos principais pontos da campanha do Reino Unido para o desmembramento, mesmo este não fazendo parte do Espaço Schengen (RIJO, 2017).

Para COSTA (2017) “a UE não é um agente estático, mas sim dinâmico, que evolui de acordo com o ritmo do contexto internacional". O bloco europeu tem enfrentado uma situação paradoxal ao longo dos últimos anos. Há uma concordância da maioria dos líderes nacionais de que somente a adoção de medidas comuns entre os Estados Membros é capaz de solucionar crises financeiras, desemprego e as migraçôes de maneira efetiva, por outro lado cresceu a posição crítica destes quanto à relação de integração, e com ela a retórica "anti-UE" tem se tornado cada vez comum entre as principais mídias e tomado a opinião pública (COSTA, 2017). 
As críticas levantadas por organismos de proteção internacional como o ACNUR, não se restringem aos Estados da Uniáo Europeia, observa-se em um âmbito global a falta de solidariedade internacional sobre crises migratórias em diversas regiôes. Relatores da ONU sugerem um pacto global, considerando as especificidades regionais dadas à natureza do fenômeno, para que se possa avançar em termos de proteção. É necessário ressaltar que as migrações internacionais implicam uma mudança do indivíduo entre duas entidades, ou sistemas políticos diferentes. Nesse sentido pode-se afirmar que estas são um fenômeno inerentemente político e não apenas social, "que advém da organização do mundo num conjunto de Estados soberanos mutuamente exclusivos, comumente chamado de sistema westphaliano" (ZOLBERG,1999, p. 81 apud REIS, 2004). Reconhecer a importância do Estado nas migrações internacionais não significa afirmar que ele é o fator mais relevante na formação e manutenção dos fluxos migratórios, mas, sobretudo é compreender que o Estado ou conjunto de Estados dispostos em regimes de cooperação ou ainda complexos de integração regional como a UE, por meio de políticas de imigração e cidadania, é um importante fator explicativo no processo de formação dos fluxos e ajudam a moldar a forma que estes fluxos migratórios irão adquirir (ONU BRASIL, 2017; REIS, 2004).

\section{Considerações finais}

O presente trabalho buscou analisar os impactos institucionais gerados pela crise de refugiados na União Europeia e identificar como estes impactos interferem nas relações de integração do bloco. Para isso foi necessária a elucidaçáo acerca do Direito Comunitário existente entre os Estados Membros da União Europeia, e seu Sistema Europeu Comum de Asilo.
A inadequação da regulamentação da Convenção de Dublin frente o atual fenômeno migratório da regiáo pode ser considerada uma grande falha do processo integrativo, pois a sua configuração original é injusta e disfuncional. Esta produziu consequências sérias às relaçôes dos Estados Membros no ápice da crise dos refugiados em 2015 e em seu desdobramento nos anos seguintes. Com base nas tensôes geradas a partir das responsabilidades desproporcionais atribuídas aos Estados, infere-se que a UE não conseguiu desenvolver plenamente uma política comum de asilo e ao contrário do que se esperava no âmbito da proteçáo internacional, gerou o endurecimento das políticas de migração e refúgio, feriram em vários aspectos os princípios internacionais de proteçấo e contribuiu para o aumento das discriminaçốes aos imigrantes irregulares e solicitantes de refúgio que chegam a Europa.

Nas atuais condições das instituições da UE, bem como na relaçáo entre os Estados Membros, a garantia da efetiva proteçẫo dos direitos humanos para os refugiados encontra-se extremamente fragilizada. Esta crise humanitária tem sido experienciada de formas diferentes por diferentes atores, havendo uma divisão de posiçōes na Europa e no mundo, mas é certo dizer que enquanto houver problemas de harmonização das medidas de proteção seja na UE seja na comunidade internacional como um todo, o desafio de proteçâo permanecerá. A solidariedade internacional e ação conjunta de todos os membros da UE precisam ser a base do Sistema Europeu Comum de Asilo, para que os imigrantes que chegam à Europa sejam de fato integrados conforme prevê do Direito Internacional e para que o ideal integrativo permaneça.

\section{Referências}

ACNUR. Desperate Journeys. January 2017 - march 2018. Genebra, 2018. Disponível em: <http://www.acnur.org/portugues/2018/04/11/relatorio-do-acnur-revela-mudancas-do-movimento-migratorio-na-europa/>. Acesso em: 20. Jun. 2018. 
ANSA BRASIL. Comissáo aprova reforma da Convençáo de Dublim sobre asilo: A medida é um pleito antigo de países como a Itália e Grécia. 2017. Disponível em: <http:// ansabrasil.com.br/brasil/noticias/italia/noticias/2017/10/19/ comissao-aprova-reforma-da-convencao-de-dublin-sobre-asilo_f47912fe-f14d-465d-8a09-66365df475ca.html>. Acesso em: 06 nov. 2018.

ARIAS, Carlota Sofia. Refugiados na União Europeia: Análise da Política Europeia para os Refugiados. 2014. 87 f. Dissertação (Mestrado) Programa de Pós-Graduação em Ciências Políticas e Relações Internacionais, Universidade Nova de Lisboa. Lisboa, 2017. Disponível em < https:// run.unl.pt/bitstream/10362/24351/1/Tese_CPRI_a43965_ CarlotaGarza.pdf> Acesso em 24. Out. 2018

COMISSÃO EUROPEIA. Regulamento do Parlamento Europeu e do Conselho Relativo à Criação do Sistema Eurodac de Comparação de Impressões Digitais. Bruxelas, 2016.

CONSELHO EUROPEU. Declaração UE-Turquia, 2016. Disponível em: <http://www.consilium.europa.eu/pt/policies/ migratory-pressures/countries-origin-transit/eu-turkey-statement/>. Acesso em 12. jun.18.

COSTA, Oliver. A Uniáo Europeia e sua política exterior: história, instituiçóes e processo de tomada de decisão. Brasília: Funag, 2017. 224 p.. Disponível em: <http://funag. gov.br/loja/download/1189-Uniao_europeia_e_sua_politica_ exterior.pdf>. Acesso em: 02 out. 2018.

EUROSTAT. Asylum decisions in the EU. 2015. Disponível em: <https://ec.europa.eu/eurostat/documents/2995521/7233417/3-20042016-AP-EN.pdf/34c4f5af-eb93-4ecd-984c-577a5271c8c5> . Acesso em: 09. out. 2018.

LIMA FILHO, Francisco das C.. A Ordem Jurídica Comunitária Europeia: Princípios e Fontes. Revista Jurídica UNIGRAN. Dourados, MS, v. 8, n. 15,| Jan./Jun. 2006.

MAMEDE, Anna Paula Ribeiro Araujo. Os Novos Poderes Institucionais do Parlamento Europeu e a Política Migratória Europeia Após o Tratado de Lisboa. 2014. 130 f. Dissertação (Mestrado) - Programa de Pós-Graduação em Relações Internacionais, Pontifícia Universidade Católica de Minas Gerias, Belo Horizonte, 2014. Disponível em: < http:// opiniaopublica.ufmg.br/site/files/biblioteca/RelInternac-MamedeAP.pdf> Acesso: 12.jun.2018.

MENDES, Sara Ribeiro. A Cláusula de Soberania do Regulamento Dublin III à Luz do Princípio da Confiança Mútua entre os Estados-Membros da Uniáo Europeia. 2016. 97 f. Dissertação (Mestrado) - Programa de Pós Graduação em Direito, Universidade Nova de Lisboa, Lisboa, 2017. Disponível em: < https://run.unl.pt/bitstream/10362/21691/1/Mendes_2017.pdf> Acesso em: 23. set. 2018.

ONU BRASIL. Relatores da ONU pedem pacto global de migração focado em direitos humanos. 2017. Disponível em:< https://nacoesunidas.org/relatores-da-onu-pedem-pacto-glo- bal-de-migracao-focado-em-direitos-humanos/>. Acesso em: 30. set. 2018.

PIÇARRA, Nuno. A União Europeia e "a crise migratória sem precedentes": crônica breve de uma ruptura do Sistema Europeu Comum de Asilo. Revista e-Pública, Vol.3, n.2, p.01-40. Novembro, 2006. Disponível em: <http:// www.scielo. mec.pt/scielo.php?script=sci_arttext $\&$ pid=S2183-184X2016000200001>. Acesso em 24 .set. 2018.

REIS, Rossana Rocha. Soberania, Direitos Humanos E Migraçôes Internacionais. Revista Brasileira de Ciências Sociais, Vol. 19 No. 55. Junho, 2004. Disponível em < http://www. scielo.br/pdf/rbcsoc/v19n55/a09v1955.pdf> Acesso em 24. out. 2018

RIJO, Diana Filipa Rodrigues. A Uniáo Europeia face à crise dos migrantes e refugiados: Um ator dividido sob escrutínio. 2017. 218 f. Dissertaçáo (Mestrado) - Curso de Relaçôes Internacionais, Universidade do Minho, Braga, 2017. Disponível em: <https://repositorium.sdum.uminho.pt/bitstream/1822/46741/1/Diana\%20Filipa\%20Rodrigues\%20 Rijo.pdf>. Acesso em 28. set. 2018.

UNIÃO EUROPEIA. Convençáo sobre a determinaçáo do Estado Responsável pela análise de um pedido de asilo apresentado num Estado-Membro das Comunidades Europeias. Dublin, 1992. Disponível em: <https://eur-lex.europa.eu/legal-content/PT/ALL/?uri=celex\%3A41997A0819\%2801\%29>. Acesso em 26. set. 2018. 